\title{
Factors Associated with a Large Decline in Renal Function or Progression to Renal Insufficiency in Hospitalized Atrial Fibrillation Patients with Early-Stage CKD
}

\author{
Lili Hu, ${ }^{1,2, *}$ MD, Qinmei Xiong, ${ }^{1, *}$ MD, Zhiqing Chen, ${ }^{1, *}$ MD, Linghua Fu, ${ }^{1} \mathrm{MD}$, Jinzhu Hu, ${ }^{1} \mathrm{MD}$, \\ Qi Chen, ${ }^{1} \mathrm{MD}$, Weiping Tu, ${ }^{2} \mathrm{MD}$, Chengyun $\mathrm{Xu},{ }^{2} \mathrm{MD}$, Gaosi $\mathrm{Xu},{ }^{2} \mathrm{MD}$, \\ Juxiang $\mathrm{Li},{ }^{1}$ MD and Kui Hong, ${ }^{1,3}$ MD
}

\begin{abstract}
Summary
Clinicians must consider renal function when administering anticoagulants for atrial fibrillation (AF). Determination of risk factors for renal function decline may enable identification of patients who require closer monitoring. We investigated the characteristics associated with renal function decline in patients with AF. The study cohort consisted of $631 \mathrm{AF}$ patients who had at least one readmission during the follow-up period and stages 1-3 chronic kidney disease (CKD). The primary outcome measure was large renal function decline ( $\geq$ $30 \%$ decrease from baseline estimated glomerular filtration rate [eGFR]). The secondary outcome measure was a final eGFR $<60 \mathrm{~mL} /$ minute $/ 1.73 \mathrm{~m}^{2}$ for those with a baseline eGFR above this level. The mean eGFR was $74.4 \pm 18.5 \mathrm{~mL} /$ minute $/ 1.73 \mathrm{~m}^{2}$, and the mean follow-up time was $30.2 \pm 13.2$ months. The primary outcome occurred in 155 patients $(24.6 \%)$ and was associated with congestive heart failure (CHF), proteinuria, type of $\mathrm{AF}$, and left atrial diameter $(\mathrm{LAD}) \geq 45 \mathrm{~mm}$. Among 478 patients with a baseline eGFR $\geq 60 \mathrm{~mL} /$ minute/1.73 $\mathrm{m}^{2}, 137(28.7 \%)$ progressed to renal failure (eGFR $<60 \mathrm{~mL} /$ minute $/ 1.73 \mathrm{~m}^{2}$ ). A decreasing eGFR was associated with age $\geq 75$ years, CHF, lower baseline eGFR, and LAD $\geq 45 \mathrm{~mm}$. CHF, proteinuria, type of AF, and LAD $\geq 45 \mathrm{~mm}$ were associated with eGFR decline $\geq 30 \%$ in AF patients with CKD stages 1-3. Advanced age, $\mathrm{CHF}$, lower baseline eGFR, and LAD $\geq 45 \mathrm{~mm}$ were associated with progression to renal insufficiency. These results should be considered when identifying patients who require more frequent monitoring of eGFR.
\end{abstract}

(Int Heart J 2020; 61: 239-248)

Key words: Left atrial diameter, eGFR decline

A trial fibrillation (AF), the most common type of cardiac arrhythmia, affects $8 \%-10 \%$ of individuals older than 75 years and increases the risk of stroke and all-cause mortality. ${ }^{1)}$ Renal insufficiency is a common co-morbidity in patients with $\mathrm{AF}$ that has a major adverse impact on clinical outcomes. ${ }^{2,3}$ Reduced renal function may also be associated with AF complications. In particular, a study that followed 617 patients with $\mathrm{AF}$ for more than 2 years reported that a decline in the estimated glomerular filtration rate (eGFR) of $25 \%$ or more over 6 months was associated with a more than two-fold increase in the rate of stroke and death. ${ }^{4)}$ Diagnosis and evaluation of renal function is a key component of AF management, especially for patients taking novel oral anticoagulants (NOACs).

Previous studies of patients with AF reported the following risk factors were associated with renal outcome, based on different definitions of worsening renal function: anticoagulation therapy, ${ }^{5)}$ chronic kidney disease (CKD), ${ }^{6}$ coronary artery disease (CAD), ${ }^{6}$ old age, ${ }^{7)}$ ratio of early mitral inflow velocity to global diastolic strain rate, ${ }^{8)}$ ankle-brachial pressure index, ${ }^{9}$ and $\mathrm{CHA}_{2} \mathrm{DS}_{2}$-VASc score. ${ }^{10)}$ Other studies reported that echocardiographic measures of impaired left ventricular function ${ }^{11)}$ and increased left atrial diameter (LAD) ${ }^{12}$ predict progression to dialysis or faster renal function decline in patients with and without $\mathrm{AF}$ who have $\mathrm{CKD}$ stages 3-5.

However, few studies have evaluated the association between echocardiographic parameters and renal outcome in AF patients with early-stage CKD. We performed a retrospective, case-control study to investigate changes in the eGFR over time and the relationship between the echocardiographic parameters and renal function decline in hospitalized AF patients with CKD stages 1-3.

From the ${ }^{1}$ Department of Cardiovascular Medicine, The Second Affiliated Hospital of Nanchang University, Nanchang, China, ${ }^{2}$ Department of Nephrology, The Second Affiliated Hospital of Nanchang University, Nanchang, China and ${ }^{3}$ Jiangxi Key Laboratory of Molecular Medicine, Nanchang, China.

*These authors contributed equally to this work.

This work was supported by National Natural Science Foundation of China (Grant No. 81530013 and 81600243), National Key R\&D Program of China (2017YFC1307804), Jiangxi Provincial Science Foundation (210171ACB20033).

Address for correspondence: Kui Hong, MD, Department of Cardiovascular Medicine, The Second Affiliated Hospital of Nanchang University, No.1 Minde Road, Nanchang, Jiangxi 330006, China. E-mail: hongkui88@163.com

Received for publication April 22, 2019. Revised and accepted November 14, 2019.

Released in advance online on J-STAGE March 14, 2020.

doi: 10.1536/ihj.19-205

All rights reserved by the International Heart Journal Association. 


\section{Methods}

Study patients: This retrospective cohort study recruited inpatients with AF from the cardiovascular department of the Second Affiliated Hospital of Nanchang University (Jiangxi, China) who had more than two measurements of serum creatinine (SCr) from June 2011 to August 2017. All patients had non-valvular AF, were at least 18 years old and had available $\mathrm{SCr}$ for more than 1 year interval. The exclusion criteria were the presence of rheumatic valvular disease or a prosthetic heart valve, an eGFR $<30$ $\mathrm{mL} /$ minute $/ 1.73 \mathrm{~m}^{2}$, and having received chemotherapy for cancer. The data extracted at baseline were the laboratory data and comorbidities (hypertension, diabetes mellitus, congestive heart failure $[\mathrm{CHF}]$, stroke/transient ischemic attack [TIA], CAD, peripheral artery disease [PAD], and chronic obstructive pulmonary disease [COPD]). The presence of proteinuria was defined by a urine dipstick test result of $1+$ or higher. Information on the use of medications during the study period, including antiplatelet drugs, NOACs, warfarin, angiotensin-converting enzyme inhibitors (ACEIs), angiotensin II receptor blockers (ARBs), $\beta$ blockers, calcium channel blockers, diuretics, and HMGCoA reductase inhibitors (statins), was obtained from the medical records.

Echocardiography was used to measure LAD, left ventricular end-diastolic dimension (LVEDd), left ventricular end-systolic dimension (LVESd), left ventricular posterior wall thickness (LVPWT), interventricular septal thickness (IVST), and left ventricular ejection fraction (LVEF). Left ventricular mass (LVM) was calculated using the standard formula: $\left.{ }^{13}\right) \operatorname{LVM}(\mathrm{g})=0.8 \times 1.04$ $\left[\left(\right.\right.$ LVEDd + IVST + LVPWT $^{3}-$ LVEDd $\left.^{3}\right]+0.6$. The baseline stroke risk was assessed using the $\mathrm{CHADS}_{2}$ score (in which 1 point was given for $\mathrm{CHF}$, hypertension, age 75 years or older, and diabetes mellitus and 2 points for a history of stroke/TIA/thromboembolism) and the $\mathrm{CHA}_{2}$ $\mathrm{DS}_{2}$-VASc score (in which 1 point was given for $\mathrm{CHF}$, hypertension, diabetes mellitus, age of 65-74 years, vascular disease, and female sex and 2 points for age of 75 years or older and previous stroke/TIA/thromboembolism). ${ }^{14}$

The reasons for readmission include stroke/TIA; CHF; myocardial infarction; new angina; AF or other supraventricular arrhythmia; ventricular arrhythmia; implantation of a pacemaker; syncope; surgery (catheter ablation for $\mathrm{AF}$, percutaneous transluminal coronary angioplasty, lower extremity arterial thrombectomy, or other); other non-cardiovascular cause (gastrointestinal, diabetic, injury/ fall, fracture, psychiatric, hematologic, genitourinary, or other); and non-severe infection. Major bleeding was defined as a reduction in the hemoglobin level of at least 2 $\mathrm{g} / \mathrm{L}$, transfusion of at least two units of blood, or intracranial bleeding.

Renal outcomes: At baseline and the last follow-up, $\mathrm{SCr}$ was measured by the same laboratory, and measurements were also recorded at hospital admission. The mean follow-up was $30.2 \pm 13.2$ months, with a mean of $2.5 \pm$ 1.9 measurements per patient. The eGFR was calculated using the CKD Epidemiology (CKD-EPI) collaboration equation. ${ }^{15)}$ All patients were classified into four eGFR categories according to the Kidney Disease: Improving
Global Outcomes guidelines: ${ }^{16}$ normal renal function (eGFR $\geq 90 \mathrm{~mL} / \mathrm{minute} / 1.73 \mathrm{~m}^{2}$, CKD stage 1 ), mild reduction of eGFR (60-89 mL/minute $/ 1.73 \mathrm{~m}^{2}$, CKD stage $2)$, moderate reduction in eGFR $(30-59 \mathrm{~mL} /$ minute $/ 1.73$ $\mathrm{m}^{2}$, CKD stage 3), and severe reduction in eGFR $(<30$ $\mathrm{mL} / \mathrm{minute} / 1.73 \mathrm{~m}^{2}$, CKD stages 4-5). Longitudinal changes in eGFR were determined during the follow-up period, based on two measures of renal function. The sequential change in eGFR at the last follow-up was calculated as the relative difference. The relative difference was defined as (eGFR at the last measure - eGFR at baseline)/ eGFR at baseline. The annual rate of renal function decline $(\Delta \mathrm{eGFR} / \mathrm{year})$ was defined as (eGFR at the last measure - eGFR at baseline)/eGFR at baseline/follow-up period. The primary endpoint was $a \geq 30 \%$ decrease in eGFR, based on the previous finding that this decrease predicts subsequent end-stage renal disease. ${ }^{17)}$ A secondary analysis, which excluded 153 patients, examined the development of an incident eGFR $<60 \mathrm{~mL} /$ minute $/ 1.73 \mathrm{~m}^{2}$, and only included patients whose eGFR was $60 \mathrm{~mL} / \mathrm{min}$ ute $/ 1.73 \mathrm{~m}^{2}$ or more at baseline.

Statistical analysis: Each continuous variable is expressed as mean $\pm \mathrm{SD}$ or as median and interquartile range, and each categorical variable is expressed as a percentage. Differences between groups were evaluated using the $\chi^{2}$ test for categorical variables and an independent $t$-test for continuous variables.

The change in the percentage of patients in each of the four eGFR categories from baseline to follow-up were determined for patients with an LAD $<45 \mathrm{~mm}$ and for patients with an LAD $\geq 45 \mathrm{~mm}$, as described previously. ${ }^{18)}$ The variables associated with large renal function decline during the follow-up period ( $\geq 30 \%$ decline in eGFR) and with the development of an eGFR $<60 \mathrm{~mL} /$ minute $/ 1.73$ $\mathrm{m}^{2}$ were identified. The independent effects of different variables on renal function were identified using multivariate logistic regression analysis. All variables with $P$-values $<0.10$ in the univariate logistic regression analysis were included as independent variables in the multivariable logistic regression analysis. A two-sided $P$-value $<0.05$ was considered to be statistically significant. All statistical analyses were performed using SPSS ver. 23 (IBM Corp).

\section{Results}

The detailed rehospitalization reasons were shown in Table I. The most common reasons for rehospitalization were cardiovascular event $(49.1 \%)$, non-cardiovascular disease $(30.3 \%)$, and non-severe infection $(11.7 \%)$. We examined the records of 631 patients who were hospitalized with AF. The mean age was $72.3 \pm 8.9$ years, 289 patients (45.8\%) were female, the mean $\mathrm{CHADS}_{2}$ score was $2.4 \pm$ 1.4 , and the mean $\mathrm{CHA}_{2} \mathrm{DS}_{2}$-VASc score was $3.9 \pm 1.7$. A total of $72.6 \%$ of patients had a $\mathrm{CHADS}_{2}$ score $\geq 2$, and $91.6 \%$ had a $\mathrm{CHA}_{2} \mathrm{DS}_{2}$-VASc score $\geq 2$. The overall mean baseline eGFR was $74.4 \pm 18.5 \mathrm{~mL} /$ minute $/ 1.73 \mathrm{~m}^{2}$. In addition, $54.2 \%$ of patients $(n=342)$ had mild renal impairment (eGFR $60-89 \mathrm{~mL} /$ minute $/ 1.73 \mathrm{~m}^{2}$ ) and $24.2 \%$ of patients $(n=153)$ had moderate renal impairment (eGFR $30-59 \mathrm{~mL} /$ minute $/ 1.73 \mathrm{~m}^{2}$ ).

Factors associated with large decline in renal function: 
Table I. Reasons for Hospitalization

\begin{tabular}{|c|c|c|c|}
\hline Characteristic & $\begin{array}{c}\text { Overall } \\
(n=631)\end{array}$ & $\begin{array}{c}\text { eGFR decline }<30 \% \\
(n=476)\end{array}$ & $\begin{array}{c}\text { eGFR decline } \geq 30 \% \\
(n=155)\end{array}$ \\
\hline \multicolumn{4}{|l|}{ Patients with a cardiovascular hospitalization } \\
\hline Congestive heart failure & $102(16.2 \%)$ & $70(14.7 \%)$ & $32(20.6 \%)$ \\
\hline Ischemic stroke or TIA & $97(15.4 \%)$ & $73(15.3 \%)$ & $24(15.5 \%)$ \\
\hline AF and other supraventricular rhythm disorders & $71(11.3 \%)$ & $56(11.8 \%)$ & $15(9.7 \%)$ \\
\hline Ventricular arrhythmia & $6(1.0 \%)$ & $5(1.1 \%)$ & $1(0.6 \%)$ \\
\hline New angina & $9(1.4 \%)$ & $5(1.1 \%)$ & $4(2.6 \%)$ \\
\hline Myocardial infarction & $10(1.6 \%)$ & $5(1.1 \%)$ & $5(3.2 \%)$ \\
\hline Implantation of a pacemaker & $10(1.6 \%)$ & $5(1.1 \%)$ & $5(3.2 \%)$ \\
\hline Syncope & $5(0.8 \%)$ & $3(0.6 \%)$ & $2(1.3 \%)$ \\
\hline Patients with hospitalization due to any bleeding & $16(2.5 \%)$ & $11(2.3 \%)$ & $5(3.2 \%)$ \\
\hline Patients hospitalized for non-cardiovascular reason & $191(30.3 \%)$ & $164(34.5 \%)$ & $27(17.4 \%)$ \\
\hline Non-severe infection & $74(11.7 \%)$ & $50(10.5 \%)$ & $24(15.5 \%)$ \\
\hline Surgery & $40(6.3 \%)$ & $29(6.1 \%)$ & $11(7.1 \%)$ \\
\hline
\end{tabular}

Table II compares the baseline characteristics of all patients $(n=631)$, those with a small eGFR decline $(<30 \%$, $n=476)$, and those with a large eGFR decline $(\geq 30 \%, n$ $=155)$. The mean decline in eGFR was $2.4 \% \pm 7.0 \%$ per year in patients with a small eGFR decline and $20.5 \% \pm$ $9.9 \%$ per year in patients with a large eGFR decline $(P=$ 0.000). Relative to patients with a small eGFR decline, those with a large decline were older, more likely to have persistence or permanent $\mathrm{AF}, \mathrm{CHF}$, proteinuria, and a high level of brain natriuretic peptide and to use an ACEI and/ or ARB, a diuretic, and a $\beta$-blocker. In addition, patients with a large eGFR decline had significantly increased LAD, LVEDd, LVESd, and LVM, and lower LVEF. The use of anticoagulants was not different between the two groups. Interestingly, although eGFR at baseline was lower in the group with the large eGFR decline, the two groups had no significant difference in $\mathrm{SCr}$ at baseline.

Table III shows the results of univariate and multivariate analyses of the factors associated with a large eGFR decline. The univariate analysis showed that a large eGFR decline had significant positive correlations with baseline eGFR and LVEF and significant negative correlations with persistence or permanent $\mathrm{AF}, \mathrm{CHF}$, proteinuria, LAD, LVEDd, LVESd, LVM, and use of a $\beta$-blocker, a diuretic, and an ACEI and/or ARB. The multivariate analysis indicated that a large eGFR decline was independently associated with type of $\mathrm{AF}, \mathrm{CHF}$, proteinuria, and $\mathrm{LAD} \geq 45 \mathrm{~mm}$ after adjustment for potential confounders.

Effect of LAD on changes in renal function: We compared the decline of renal function in patients who had a large LAD ( $\geq 45 \mathrm{~mm}, n=190$ ) with those who had a small LAD ( $<45 \mathrm{~mm}, n=434)$ (Figure 1). Most patients experienced a decreased eGFR, and there was a parallel increase in the prevalence of moderate and severe renal dysfunction in both groups. A total of $13.7 \%$ of the patients with a large LAD progressed to severe renal impairment, but only $6.2 \%$ of those with a small LAD progressed to severe renal impairment $(P=0.002)$.

We also analyzed the effect of LAD in a subgroup of patients $(n=492)$ who had an LVEF $\geq 50 \%$ (Figure 2$)$. Patients with a large LAD had a $19.4 \%$ decline in eGFR, but those with a small LAD had an $11.5 \%$ decline in
eGFR $(P=0.003)$. Thus, patients who had left atrial dilation experienced greater reductions in eGFR.

Risk of progression to low eGFR $(<60 \mathrm{~mL} / \mathrm{minute} / 1.73$ $\left.\mathbf{m}^{2}\right)$ : At baseline, $478(75.8 \%)$ patients had an eGFR $\geq 60$ $\mathrm{mL} /$ minute/1.73 $\mathrm{m}^{2}$. During follow-up (mean duration: $30.5 \pm 13.1$ months), $137(28.7 \%)$ patients with an eGFR $\geq 60 \mathrm{~mL} /$ minute $/ 1.73 \mathrm{~m}^{2}$ developed an eGFR $<60 \mathrm{~mL} /$ minute/1.73 $\mathrm{m}^{2}$ (Table IV); these patients were older, more likely to have $\mathrm{CHF}$ and $\mathrm{CAD}$, had higher levels of brain natriuretic peptide and $\mathrm{SCr}$, had higher $\mathrm{CHADS}_{2}$ and $\mathrm{CHA}_{2} \mathrm{DS}_{2}$-VASc scores, and were more likely to use a $\beta$ blocker and a diuretic. Echocardiography indicated that patients with an eGFR $<60 \mathrm{~mL} /$ minute $/ 1.73 \mathrm{~m}^{2}$ had a lower mean LVEF and a greater mean LAD, LV dimension, and LVM than those with an eGFR $\geq 60 \mathrm{~mL} /$ minute/ $1.73 \mathrm{~m}^{2}$. There was no significant difference in the use of anticoagulants between two groups.

Table V displays the results of univariate and multivariate analyses of factors associated with progression to an eGFR $<60 \mathrm{~mL} /$ minute $/ 1.73 \mathrm{~m}^{2}$. $\mathrm{CHADS}_{2}$ and $\mathrm{CHA}_{2}$ $\mathrm{DS}_{2}$-VASc scores were excluded from the multivariate analysis because the other factors in the model already considered age, sex, CAD, and CHF. The multivariate analysis indicated that an eGFR $<60 \mathrm{~mL} /$ minute $/ 1.73 \mathrm{~m}^{2}$ at follow-up correlated independently with age of 75 years or more, CHF, an initial eGFR $<90 \mathrm{~mL} /$ minute $/ 1.73 \mathrm{~m}^{2}$, and $\mathrm{an} \mathrm{LAD} \geq 45 \mathrm{~mm}$.

\section{Discussion}

The present retrospective longitudinal cohort "realworld" study of patients hospitalized with AF indicated that $24.6 \%$ of patients with early-stage CKD experienced a decrease of eGFR $\geq 30 \%$ from baseline. This is similar to the value of $24.4 \%$ reported by Yao and colleagues. ${ }^{5}$ ) Moreover, $28.7 \%$ of patients with normal or mild loss of renal function (eGFR $\geq 60 \mathrm{~mL} /$ minute $/ 1.73 \mathrm{~m}^{2}$ ) at baseline experienced a decline in renal function to moderate/severe renal insufficiency (eGFR $<60 \mathrm{~mL} /$ minute $/ 1.73 \mathrm{~m}^{2}$ ). CHF, proteinuria, and type of AF were associated with a large decline in renal function; older age, $\mathrm{CHF}$, and lower baseline eGFR were associated with progression to renal insufficiency. In addition, an LAD $\geq 45 \mathrm{~mm}$ was independ- 
Table II. Baseline Characteristics of Patients Who Did and Did Not Have a Large Decline of eGFR ( $\geq 30 \%)$ at Follow-Up

\begin{tabular}{|c|c|c|c|c|}
\hline Characteristic & $\begin{array}{l}\text { Overall } \\
(n=631)\end{array}$ & $\begin{array}{c}\text { eGFR decline }<30 \% \\
(n=476)\end{array}$ & $\begin{array}{c}\text { eGFR decline } \geq 30 \% \\
(n=155)\end{array}$ & $P$ value \\
\hline$\Delta$ eGFR/year & $6.8 \% \pm 11.0 \%$ & $2.4 \% \pm 7.0 \%$ & $20.5 \% \pm 9.9 \%$ & 0.000 \\
\hline Age (years) & $72.3 \pm 8.9$ & $71.9 \pm 9.0$ & $73.5 \pm 8.6$ & 0.062 \\
\hline Age $\geq 75$ years & $290(46.0 \%)$ & $213(44.7 \%)$ & $77(49.7 \%)$ & 0.285 \\
\hline Atrial fibrillation & & & & 0.005 \\
\hline Paroxysmal & $415(65.8 \%)$ & $329(69.1 \%)$ & $86(55.5 \%)$ & \\
\hline Persistence & $173(27.4 \%)$ & $120(25.2 \%)$ & $53(34.2 \%)$ & \\
\hline Permanent & $43(6.8 \%)$ & $27(5.7 \%)$ & $16(10.3 \%)$ & \\
\hline Duration of AF (years) & $2.3 \pm 5.2$ & $2.3 \pm 5.2$ & $2.4 \pm 5.1$ & 0.865 \\
\hline Female sex & $289(45.8 \%)$ & $210(44.1 \%)$ & $79(51.0 \%)$ & 0.137 \\
\hline Hypertension & $437(69.3 \%)$ & $325(68.3 \%)$ & $112(72.3 \%)$ & 0.351 \\
\hline Diabetes mellitus & $136(21.6 \%)$ & $100(21.0 \%)$ & $36(23.2 \%)$ & 0.560 \\
\hline $\mathrm{CHF}$ & $288(45.6 \%)$ & $196(41.2 \%)$ & $92(59.4 \%)$ & $<0.001$ \\
\hline Previous stroke & $181(28.7 \%)$ & $142(29.8 \%)$ & $39(25.2 \%)$ & 0.264 \\
\hline CAD & $103(16.3 \%)$ & $73(15.3 \%)$ & $30(19.4 \%)$ & 0.240 \\
\hline PAD & $15(2.4 \%)$ & $13(2.7 \%)$ & $2(1.3 \%)$ & 0.472 \\
\hline COPD & $68(10.8 \%)$ & $51(10.7 \%)$ & $17(11.0 \%)$ & 0.930 \\
\hline $\mathrm{CHADS}_{2}$ score, mean & $2.4 \pm 1.4$ & $2.4 \pm 1.4$ & $2.6 \pm 1.4$ & 0.112 \\
\hline Score $\geq 2$ & $458(72.6 \%)$ & $337(70.8 \%)$ & $121(78.1 \%)$ & 0.078 \\
\hline $\mathrm{CHA}_{2} \mathrm{DS}_{2}$-VASc score, mean & $3.9 \pm 1.7$ & $3.8 \pm 1.7$ & $4.1 \pm 1.7$ & 0.041 \\
\hline Score $\geq 2$ & $578(91.6 \%)$ & $431(90.5 \%)$ & $147(94.8 \%)$ & 0.094 \\
\hline \multicolumn{5}{|l|}{ Laboratory parameters } \\
\hline Total cholesterol (mg/dL) & $150.2 \pm 32.2$ & $151.4 \pm 31.5$ & $146.5 \pm 34.1$ & 0.111 \\
\hline LDL cholesterol (mg/dL) & $89.7 \pm 29.8$ & $91.1 \pm 30.3$ & $85.6 \pm 28.1$ & 0.051 \\
\hline HDL cholesterol (mg/dL) & $39.6 \pm 11.0$ & $39.9 \pm 10.8$ & $38.8 \pm 11.6$ & 0.301 \\
\hline Proteinuria & $51(8.3 \%)$ & $29(6.2 \%)$ & $22(14.7 \%)$ & 0.001 \\
\hline Brain natriuretic peptide $(\mathrm{pg} / \mathrm{mL})$ & $337.1(146.6,648.5)$ & $287.8(140.2,589.9)$ & $474.7(198.4,714.5)$ & 0.013 \\
\hline Serum creatinine $(\mu \mathrm{mol} / \mathrm{L})$ & $82.4 \pm 25.8$ & $81.3 \pm 24.5$ & $85.9 \pm 29.3$ & 0.083 \\
\hline eGFR $\left(\mathrm{mL} /\right.$ minute $\left./ 1.73 \mathrm{~m}^{2}\right)$, mean & $74.4 \pm 18.5$ & $75.5 \pm 18.2$ & $70.8 \pm 19.0$ & 0.006 \\
\hline$\geq 90(\%)$ & $136(21.6 \%)$ & $111(23.3 \%)$ & $25(16.1 \%)$ & 0.051 \\
\hline $60-89(\%)$ & $342(54.2 \%)$ & $259(54.4 \%)$ & $83(53.5 \%)$ & - \\
\hline $30-59(\%)$ & $153(24.2 \%)$ & $106(22.3 \%)$ & $47(30.3 \%)$ & - \\
\hline \multicolumn{5}{|l|}{ Medication use } \\
\hline Antiplatelet & $252(40.6 \%)$ & $193(41.1 \%)$ & $59(39.1 \%)$ & 0.665 \\
\hline NOAC & $49(7.9 \%)$ & $36(7.7 \%)$ & $13(8.6 \%)$ & 0.706 \\
\hline Warfarin & $254(40.9 \%)$ & $192(40.9 \%)$ & $62(41.1 \%)$ & 0.964 \\
\hline$\beta$-blocker & $427(68.8 \%)$ & $308(65.5 \%)$ & $112(74.2 \%)$ & 0.048 \\
\hline Calcium channel blocker & $201(32.4 \%)$ & $149(31.7 \%)$ & $52(34.4 \%)$ & 0.532 \\
\hline Diuretic & $207(33.3 \%)$ & $141(30.0 \%)$ & $66(43.7 \%)$ & 0.002 \\
\hline ACEI and/or ARB & $337(54.4 \%)$ & $236(50.3 \%)$ & $91(60.3 \%)$ & 0.033 \\
\hline Statin & $342(55.1 \%)$ & $267(56.8 \%)$ & $75(49.7 \%)$ & 0.125 \\
\hline \multicolumn{5}{|l|}{ Echocardiographic data } \\
\hline $\operatorname{LVEF}(\%)$ & $57.5 \pm 11.9$ & $58.2 \pm 11.8$ & $55.4 \pm 11.9$ & 0.013 \\
\hline $\mathrm{LVEF}<50 \%$ & $132(21.2 \%)$ & $90(19.1 \%)$ & $42(27.3 \%)$ & 0.032 \\
\hline $\mathrm{LAD}(\mathrm{mm})$ & $41.6 \pm 7.3$ & $40.9 \pm 7.0$ & $43.5 \pm 7.7$ & $<0.001$ \\
\hline $\mathrm{LAD} \geq 45 \mathrm{~mm}(\%)$ & $190(30.4 \%)$ & $126(26.8 \%)$ & $64(41.6 \%)$ & 0.001 \\
\hline LVEDd (mm) & $49.7 \pm 7.5$ & $49.1 \pm 7.1$ & $51.6 \pm 8.2$ & $<0.001$ \\
\hline LVESd (mm) & $34.6 \pm 8.4$ & $34.0 \pm 8.2$ & $36.5 \pm 8.8$ & 0.001 \\
\hline LVPWT (mm) & $9.6 \pm 1.2$ & $9.6 \pm 1.2$ & $9.7 \pm 1.2$ & 0.307 \\
\hline $\operatorname{IVST}(\mathrm{mm})$ & $10.2 \pm 1.3$ & $10.2 \pm 1.2$ & $10.3 \pm 1.4$ & 0.688 \\
\hline $\operatorname{LVM}(\mathrm{g})$ & $181.5 \pm 55.6$ & $177.3 \pm 53.1$ & $194.0 \pm 61.1$ & 0.001 \\
\hline Follow-up period (months) & $30.2 \pm 13.2$ & $29.7 \pm 12.8$ & $31.9 \pm 14.3$ & 0.090 \\
\hline
\end{tabular}

eGFR indicates estimated glomerular filtration rate; CHF, congestive heart failure; CAD, coronary artery disease; PAD, peripheral artery disease; COPD, chronic obstructive pulmonary disease; LDL, low-density lipoprotein; HDL, high-density lipoprotein; NOACs, non-vitamin K antagonist oral anticoagulants; ACEI, angiotensin-converting enzyme inhibitor; ARB, angiotensin II receptor blocker; LVEF, left ventricular ejection fraction; LAD, left atrial diameter; LVEDd, left ventricular end-diastolic dimension; LVESd, left ventricular end-systolic dimension; LVPWT, left ventricular posterior wall thickness; IVST, interventricular septal thickness; and LVM, left ventricular mass.

ently associated with a large decline in renal function and a low eGFR $\left(<60 \mathrm{~mL} / \mathrm{minute} / 1.73 \mathrm{~m}^{2}\right)$. These results suggest that renal function should be more closely monitored in this group of patients.

Previous epidemiological studies have used the decline of eGFR as a clinical endpoint. ${ }^{19,20)}$ However, the cri- 
Table III. Logistic Regression Analysis of Factors Associated with a Large eGFR Decline ( $\geq 30 \%)$ at Follow-Up

\begin{tabular}{|c|c|c|c|c|}
\hline \multirow[t]{2}{*}{ Characteristic } & \multicolumn{2}{|c|}{ Univariate } & \multicolumn{2}{|c|}{ Multivariate } \\
\hline & OR $(95 \% \mathrm{CI})$ & $P$ value & aOR $(95 \% \mathrm{CI})$ & $P$ value \\
\hline Age $\geq 75$ years & $1.22(0.85$ to 1.75$)$ & 0.285 & - & - \\
\hline \multicolumn{5}{|l|}{ Atrial fibrillation } \\
\hline Paroxysmal & 1.00 (reference) & - & 1.00 (reference) & - \\
\hline Persistence & $1.69(1.13$ to 2.52$)$ & 0.010 & $1.58(1.04$ to 2.41$)$ & 0.032 \\
\hline Permanent & $2.27(1.17$ to 4.40$)$ & 0.015 & 2.07 (1.01 to 4.26$)$ & 0.047 \\
\hline Duration of AF (years) & $1.00(0.97$ to 1.04$)$ & 0.865 & - & - \\
\hline Female sex & $1.32(0.92$ to 1.89$)$ & 0.138 & - & - \\
\hline Hypertension & $1.21(0.81$ to 1.81$)$ & 0.351 & - & - \\
\hline Diabetes mellitus & $1.14(0.74$ to 1.75$)$ & 0.560 & - & - \\
\hline $\mathrm{CHF}$ & 2.09 (1.44 to 3.02$)$ & $<0.001$ & 2.04 (1.37 to 3.02$)$ & 0.000 \\
\hline Previous stroke & $0.79(0.52$ to 1.20$)$ & 0.265 & - & - \\
\hline CAD & $1.33(0.83$ to 2.12$)$ & 0.241 & - & - \\
\hline PAD & $0.47(0.10$ to 2.09$)$ & 0.318 & - & - \\
\hline COPD & 1.03 (0.57 to 1.84$)$ & 0.930 & - & - \\
\hline $\mathrm{CHADS}_{2}$ score, mean & $1.11(0.98$ to 1.27$)$ & 0.113 & - & - \\
\hline Score $\geq 2$ & $1.47(0.96$ to 2.25$)$ & 0.079 & - & - \\
\hline $\mathrm{CHA}_{2} \mathrm{DS}_{2}$-VASc score, mean & $1.12(1.00$ to 1.24$)$ & 0.041 & - & - \\
\hline Score $\geq 2$ & $1.92(0.88$ to 4.16$)$ & 0.099 & - & - \\
\hline \multicolumn{5}{|l|}{ Laboratory parameters } \\
\hline Total cholesterol (mg/dL) & $1.00(0.99$ to 1.00$)$ & 0.111 & - & - \\
\hline LDL cholesterol (mg/dL) & $0.99(0.99$ to 1.00$)$ & 0.051 & - & - \\
\hline HDL cholesterol (mg/dL) & $0.99(0.97$ to 1.01$)$ & 0.301 & - & - \\
\hline Proteinuria & $2.60(1.44$ to 4.67$)$ & 0.001 & $2.43(1.29$ to 4.55$)$ & 0.006 \\
\hline Brain natriuretic peptide $(\mathrm{pg} / \mathrm{mL})$ & $1.00(1.00$ to 1.01$)$ & 0.152 & - & - \\
\hline Serum creatinine $(\mu \mathrm{mol} / \mathrm{L})$ & $1.01(1.00$ to 1.01$)$ & 0.058 & - & - \\
\hline \multicolumn{5}{|l|}{ eGFR $\left(\mathrm{mL} /\right.$ minute $\left./ 1.73 \mathrm{~m}^{2}\right)$} \\
\hline$\geq 90$ & 1.00 (reference) & - & - & - \\
\hline $60-89$ & $1.42(0.86$ to 2.34$)$ & 0.166 & - & - \\
\hline $30-59$ & 1.97 (1.13 to 3.42$)$ & 0.016 & - & - \\
\hline \multicolumn{5}{|l|}{ Medication use } \\
\hline Antiplatelet & $0.92(0.63$ to 1.34$)$ & 0.665 & - & - \\
\hline NOAC & $1.14(0.59$ to 2.20$)$ & 0.707 & - & - \\
\hline Warfarin & $1.01(0.70$ to 1.46$)$ & 0.964 & - & - \\
\hline$\beta$-blocker & $1.51(1.00$ to 2.28$)$ & 0.049 & - & - \\
\hline Calcium channel blocker & $1.13(0.77$ to 1.67$)$ & 0.532 & - & - \\
\hline Diuretic & $1.81(1.24$ to 2.64$)$ & 0.002 & - & - \\
\hline ACEI and/or ARB & $1.50(1.03$ to 2.17$)$ & 0.034 & - & - \\
\hline Statin & $0.75(0.52$ to 1.08$)$ & 0.126 & - & - \\
\hline \multicolumn{5}{|l|}{ Echocardiographic data } \\
\hline $\operatorname{LVEF}(\%)$ & $0.98(0.97$ to 1.00$)$ & 0.014 & - & - \\
\hline $\mathrm{LAD} \geq 45 \mathrm{~mm}(\%)$ & $1.94(1.33$ to 2.84$)$ & 0.001 & 1.55 (1.03 to 2.32$)$ & 0.035 \\
\hline LVEDd (mm) & 1.04 (1.02 to 1.07$)$ & $<0.001$ & - & - \\
\hline LVESd (mm) & $1.04(1.01$ to 1.06$)$ & 0.001 & - & - \\
\hline LVPWT (mm) & $1.08(0.93$ to 1.26$)$ & 0.306 & - & - \\
\hline IVST (mm) & $1.03(0.89$ to 1.19$)$ & 0.688 & - & - \\
\hline $\operatorname{LVM}(\mathrm{g})$ & $1.01(1.00$ to 1.01$)$ & 0.002 & - & - \\
\hline Follow-up period (months) & $1.01(1.00$ to 1.03$)$ & 0.073 & - & - \\
\hline
\end{tabular}

eGFR indicates estimated glomerular filtration rate; OR, odds ratio; CI, confidence interval; aOR, adjusted odds ratio; $\mathrm{CHF}$, congestive heart failure; $\mathrm{CAD}$, coronary artery disease; $\mathrm{PAD}$, peripheral artery disease; COPD, chronic obstructive pulmonary disease; LDL, low-density lipoprotein; HDL, high-density lipoprotein; NOACs, non-vitamin K antagonist oral anticoagulants; ACEI, angiotensin-converting enzyme inhibitor; ARB, angiotensin II receptor blocker; LVEF, left ventricular ejection fraction; LAD, left atrial diameter; LVEDd, left ventricular end-diastolic dimension; LVESd, left ventricular end-systolic dimension; LVPWT, left ventricular posterior wall thickness; IVST, interventricular septal thickness; and LVM, left ventricular mass.

teria used to define a decline of eGFR vary widely among previous studies, making comparisons difficult. We selected $\mathrm{a} \geq 30 \%$ decline in the eGFR as the endpoint, based on the December 2012 scientific workshop co- sponsored by the National Kidney Foundation and the US Food and Drug Administration. This workshop concluded that a $30 \%$ to $40 \%$ decline in the eGFR over 2 to 3 years is an acceptable clinical endpoint for CKD progression. ${ }^{17)}$ 
$\mathrm{LAD}<45 \mathrm{~mm}$

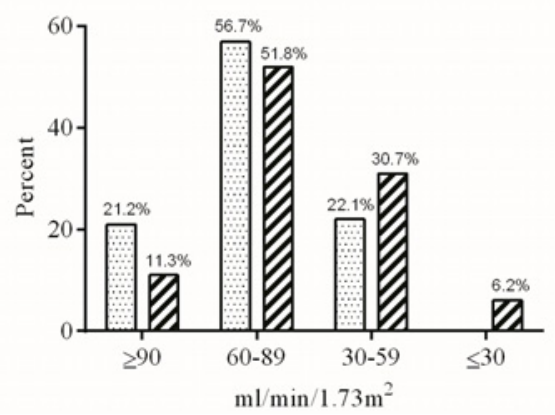

$\mathrm{LAD} \geq 45 \mathrm{~mm}$

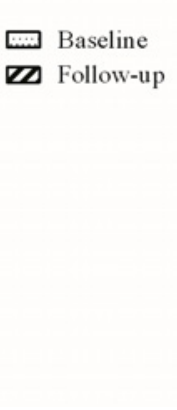

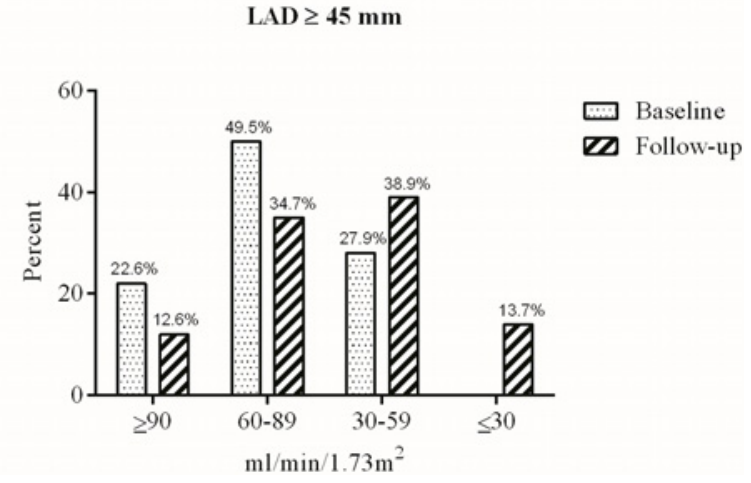

Figure 1. Distribution of eGFR in patients with $\mathrm{LAD}<45 \mathrm{~mm}(\mathbf{A})$ and $\geq 45 \mathrm{~mm}(\mathbf{B})$ at baseline and follow-up.

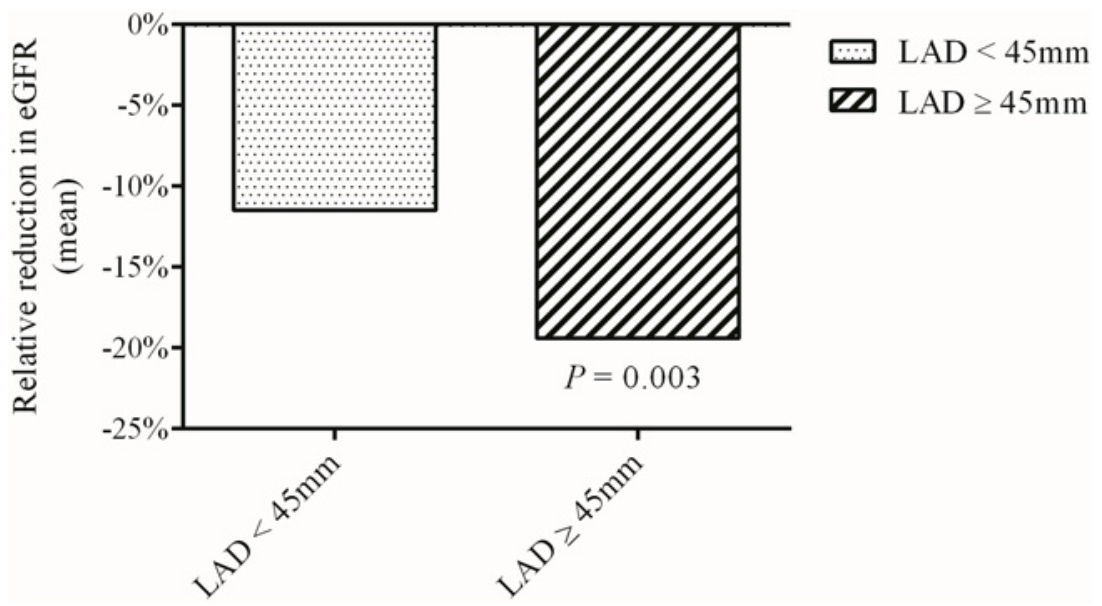

Figure 2. Relative reduction of eGFR in patients with $\mathrm{LAD}<45 \mathrm{~mm}$ and $\geq 45 \mathrm{~mm}$ groups.

We also determined whether echocardiographic parameters can predict large loss of renal function in $\mathrm{AF}$ patients with CKD stages 1-3. Our results showed that an increased LAD at baseline was associated with an eGFR decline $\geq 30 \%$ and with an incident eGFR $<60 \mathrm{~mL} / \mathrm{min}$ ute $/ 1.73 \mathrm{~m}^{2}$. Relative to patients with an LAD $<45 \mathrm{~mm}$, those with an LAD $\geq 45 \mathrm{~mm}$ were more likely to progress to severe renal impairment. In addition, our analysis of the subgroup of patients with an LVEF $\geq 50 \%$ indicated those with an LAD $\geq 45 \mathrm{~mm}$ experienced greater reductions in eGFR. AF is frequently associated with LA enlargement in patients with organic heart disease and in those with AF but no underlying disease. ${ }^{21)}$ However, it is difficult to establish a causal relationship between $\mathrm{AF}$ and LA remodeling, ${ }^{22}$ because AF frequently accompanies hypertension, $\mathrm{CHF}$, and diabetes mellitus, all of which can lead to changes in the left atrial structure and function. Our cohort had high baseline prevalence of other comorbid illnesses (hypertension: $69.3 \%$, CHF: $45.6 \%$, diabetes mellitus: $21.6 \%$ ), similar to previous reports. ${ }^{23)}$ In addition, $30.4 \%$ of our patients had an LAD $\geq 45 \mathrm{~mm}$, similar to the $31 \%$ reported in the AFFIRM trial. ${ }^{18)}$
Recent studies have reported that an enlarged left atrium is an independent predictor of adverse cardiovascular outcomes (stroke, AF, CHD, and cardiovascular death) in patients with various pathologic conditions. ${ }^{24,25}$ The Fushimi AF Registry, a large community-based prospective cohort study, found that an LAD > $45 \mathrm{~mm}$ was an independent predictor of stroke/systemic embolism. ${ }^{26)}$ Interestingly, a multivariate analysis by Chen, et al. demonstrated that an enlarged LAD was independently associated with progression to end-stage renal disease, implying that LA enlargement is a better predictor of CKD. ${ }^{12)} \mathrm{Fu}-$ rukawa, et al. determined that the LA volume index was an independent risk factor for progression to hemodialysis in 140 patients with CKD stages 4-5.27) Another cohort study of 121 patients undergoing peritoneal dialysis reported that an LA volume index $>32 \mathrm{~mL} / \mathrm{m}^{2}$ was significantly associated with more rapid decline in residual renal function. $^{28)}$

We found that an older age, CHF, albuminuria, type of AF, and a lower baseline eGFR were associated with a large decline in eGFR. Previous studies also reported correlations of $\mathrm{CHF}$ and baseline eGFR with decline in renal 
Table IV. Baseline Characteristics of Patients Who Did and Did Not Develop a Low eGFR $\left(<60 \mathrm{~mL} /\right.$ minute $\left./ 1.73 \mathrm{~m}^{2}\right)$ at Follow-Up

\begin{tabular}{|c|c|c|c|}
\hline Characteristic & No $(n=341)$ & Yes $(n=137)$ & $P$ value \\
\hline Age (years) & $70.3 \pm 9.3$ & $73.9 \pm 8.1$ & $<0.001$ \\
\hline$\geq 75$ years & $120(35.2 \%)$ & $74(54.0 \%)$ & $<0.001$ \\
\hline Atrial fibrillation & & & 0.118 \\
\hline Paroxysmal & $233(68.3 \%)$ & $80(58.4 \%)$ & \\
\hline Persistence & $89(26.1 \%)$ & $47(34.3 \%)$ & \\
\hline Permanent & $19(5.6 \%)$ & $10(7.3 \%)$ & \\
\hline Duration of AF (years) & $2.4 \pm 5.1$ & $2.8 \pm 6.3$ & 0.441 \\
\hline Female sex & $151(44.3 \%)$ & $72(52.6 \%)$ & 0.101 \\
\hline Hypertension & $222(65.1 \%)$ & $98(71.5 \%)$ & 0.177 \\
\hline Diabetes mellitus & $68(19.9 \%)$ & $34(24.8 \%)$ & 0.239 \\
\hline $\mathrm{CHF}$ & $122(35.8 \%)$ & $77(56.2 \%)$ & $<0.001$ \\
\hline Previous stroke & $96(28.2 \%)$ & $37(27.0 \%)$ & 0.801 \\
\hline CAD & $44(12.9 \%)$ & $29(21.2 \%)$ & 0.023 \\
\hline PAD & $8(2.3 \%)$ & $2(1.5 \%)$ & 0.796 \\
\hline COPD & $35(10.3 \%)$ & $10(7.3 \%)$ & 0.316 \\
\hline $\mathrm{CHADS}_{2}$ score, mean & $2.1 \pm 1.3$ & $2.6 \pm 1.4$ & 0.001 \\
\hline Score $\geq 2$ & $214(62.8 \%)$ & $106(77.4 \%)$ & 0.002 \\
\hline $\mathrm{CHA}_{2} \mathrm{DS}_{2}$-VASc score, mean & $3.5 \pm 1.8$ & $4.2 \pm 1.7$ & $<0.001$ \\
\hline Score $\geq 2$ & $296(86.8 \%)$ & $131(95.6 \%)$ & 0.005 \\
\hline \multicolumn{4}{|l|}{ Laboratory parameters } \\
\hline Total cholesterol (mg/dL) & $152.4 \pm 32.7$ & $145.7 \pm 31.4$ & 0.043 \\
\hline LDL cholesterol (mg/dL) & $91.1 \pm 30.5$ & $88.1 \pm 28.3$ & 0.325 \\
\hline HDL cholesterol (mg/dL) & $40.0 \pm 10.6$ & $38.9 \pm 11.4$ & 0.365 \\
\hline Proteinuria & $15(4.5 \%)$ & $11(8.3 \%)$ & 0.106 \\
\hline Brain natriuretic peptide $(\mathrm{pg} / \mathrm{mL})$ & $228.3(120.2,451.2)$ & $354.0(189.3,665.2)$ & 0.007 \\
\hline Serum creatinine $(\mu \mathrm{mol} / \mathrm{L})$ & $70.1 \pm 15.1$ & $76.5 \pm 16.4$ & $<0.001$ \\
\hline eGFR (mL/minute/1.73 m²) & $85.2 \pm 11.7$ & $76.2 \pm 11.4$ & $<0.001$ \\
\hline \multicolumn{4}{|l|}{ Medication use } \\
\hline Antiplatelet & $133(39.6 \%)$ & $61(45.5 \%)$ & 0.238 \\
\hline NOACs & $25(7.4 \%)$ & $11(8.2 \%)$ & 0.777 \\
\hline Warfarin & $137(40.8 \%)$ & $54(40.3 \%)$ & 0.925 \\
\hline$\beta$-blocker & $210(62.5 \%)$ & $99(73.9 \%)$ & 0.019 \\
\hline Calcium channel blocker & $108(32.1 \%)$ & $41(30.6 \%)$ & 0.745 \\
\hline Diuretic & $90(26.8 \%)$ & $57(42.5 \%)$ & 0.001 \\
\hline ACEI and/or ARB & $163(48.7 \%)$ & $78(58.2 \%)$ & 0.062 \\
\hline Statin & $184(54.8 \%)$ & $77(57.5 \%)$ & 0.595 \\
\hline \multicolumn{4}{|l|}{ Echocardiographic data } \\
\hline $\operatorname{LVEF}(\%)$ & $58.6 \pm 11.8$ & $56.0 \pm 11.9$ & 0.033 \\
\hline LVEF $<50 \%$ & $64(18.9 \%)$ & $31(22.6 \%)$ & 0.362 \\
\hline $\mathrm{LAD}(\mathrm{mm})$ & $40.5 \pm 6.8$ & $42.6 \pm 7.5$ & 0.002 \\
\hline $\mathrm{LAD} \geq 45 \mathrm{~mm}(\%)$ & $80(23.7 \%)$ & $56(40.9 \%)$ & $<0.001$ \\
\hline LVEDd (mm) & $48.9 \pm 6.9$ & $50.6 \pm 7.6$ & 0.019 \\
\hline LVESd (mm) & $33.7 \pm 8.0$ & $35.7 \pm 8.4$ & 0.013 \\
\hline LVPWT (mm) & $9.5 \pm 1.1$ & $9.6 \pm 1.2$ & 0.108 \\
\hline $\operatorname{IVST}(\mathrm{mm})$ & $10.1 \pm 1.2$ & $10.2 \pm 1.3$ & 0.587 \\
\hline $\operatorname{LVM}(\mathrm{g})$ & $173.6 \pm 51.3$ & $186.8 \pm 57.7$ & 0.014 \\
\hline Follow-up period (months) & $30.1 \pm 12.7$ & $31.5 \pm 14.1$ & 0.311 \\
\hline
\end{tabular}

eGFR indicates estimated glomerular filtration rate; CHF, congestive heart failure; CAD, coronary artery disease; PAD, peripheral artery disease; $C O P D$, chronic obstructive pulmonary disease; LDL, low-density lipoprotein; HDL, high-density lipoprotein; NOACs, non-vitamin K antagonist oral anticoagulants; ACEI, angiotensin-converting enzyme inhibitor; ARB, angiotensin II receptor blocker; LVEF, left ventricular ejection fraction; LAD, left atrial diameter; LVEDd, left ventricular end-diastolic dimension; LVESd, left ventricular end-systolic dimension; LVPWT, left ventricular posterior wall thickness; IVST, interventricular septal thickness; and LVM, left ventricular mass.

function. ${ }^{23)}$ The aging process adversely affects the kidneys and leads to an irreversible decline of renal function. ${ }^{29)}$ Thus, our finding that a lower baseline eGFR correlated with and predicted renal function decline was an expected result. ${ }^{30)}$ In fact, some studies have reported that the presence of proteinuria was associated with a more rapid decline of renal function. ${ }^{31,32)}$ Notably, factors such as age and $\mathrm{CHF}$ are components of the widely used 
Table V. Logistic Regression Analysis of Factors Associated with a Low eGFR $(<60 \mathrm{~mL} / \mathrm{minute} / 1.73$ $\left.\mathrm{m}^{2}\right)$ at Follow-Up

\begin{tabular}{|c|c|c|c|c|}
\hline & \multicolumn{2}{|l|}{ Univariate } & \multicolumn{2}{|c|}{ Multivariate } \\
\hline & OR $(95 \% \mathrm{CI})$ & $P$ value & aOR $(95 \% \mathrm{CI})$ & $P$ value \\
\hline Age $\geq 75$ years & $2.16(1.45$ to 3.24$)$ & $<0.001$ & 1.84 (1.17 to 2.90$)$ & 0.008 \\
\hline \multicolumn{5}{|l|}{ Atrial fibrillation } \\
\hline Paroxysmal & 1.00 (reference) & - & - & - \\
\hline Persistence & 1.54 (0.99 to 2.38$)$ & 0.053 & - & - \\
\hline Permanent & $1.53(0.68$ to 3.44$)$ & 0.299 & - & - \\
\hline Duration of AF (years) & $1.01(0.98$ to 1.05$)$ & 0.442 & - & - \\
\hline Female sex & $1.39(0.94$ to 2.07$)$ & 0.102 & - & - \\
\hline Hypertension & 1.35 (0.87 to 2.08$)$ & 0.177 & - & - \\
\hline Diabetes mellitus & $1.33(0.83$ to 2.12$)$ & 0.240 & - & - \\
\hline $\mathrm{CHF}$ & $2.30(1.54$ to 3.45$)$ & $<0.001$ & $1.89(1.20$ to 2.98$)$ & 0.006 \\
\hline Previous stroke & 0.94 (0.61 to 1.47$)$ & 0.801 & - & - \\
\hline CAD & $1.81(1.08$ to 3.04$)$ & 0.024 & - & - \\
\hline PAD & $0.62(0.13$ to 2.94$)$ & 0.544 & - & - \\
\hline COPD & $0.69(0.33$ to 1.43$)$ & 0.318 & - & - \\
\hline $\mathrm{CHADS}_{2}$ score, mean & $1.29(1.11$ to 1.49$)$ & 0.001 & - & - \\
\hline Score $\geq 2$ & $2.03(1.29$ to 3.20$)$ & 0.002 & - & - \\
\hline $\mathrm{CHA}_{2} \mathrm{DS}_{2}$-VASc score, mean & $1.28(1.14$ to 1.43$)$ & $<0.001$ & - & - \\
\hline Score $\geq 2$ & $3.32(1.38$ to 7.97$)$ & 0.007 & - & - \\
\hline \multicolumn{5}{|l|}{ Laboratory parameters } \\
\hline Total cholesterol (mg/dL) & $0.99(0.99$ to 1.00$)$ & 0.044 & - & - \\
\hline LDL cholesterol (mg/dL) & $1.00(0.99$ to 1.00$)$ & 0.324 & - & - \\
\hline HDL cholesterol (mg/dL) & $0.99(0.97$ to 1.01$)$ & 0.365 & - & - \\
\hline Proteinuria & $1.92(0.86$ to 4.30$)$ & 0.111 & - & - \\
\hline Brain natriuretic peptide $(\mathrm{pg} / \mathrm{mL})$ & $1.00(1.00$ to 1.00$)$ & 0.122 & - & - \\
\hline Serum creatinine $(\mu \mathrm{mol} / \mathrm{L})$ & $1.03(1.01$ to 1.04$)$ & $<0.001$ & - & - \\
\hline eGFR $\geq 90 \mathrm{~mL} /$ minute $/ 1.73 \mathrm{~m}^{2}$ & 1.00 (reference) & - & - & - \\
\hline eGFR $60-89 \mathrm{~mL} /$ minute $/ 1.73 \mathrm{~m}^{2}$ & $3.50(2.03$ to 6.03$)$ & $<0.001$ & $3.28(1.75$ to 6.16$)$ & $<0.001$ \\
\hline \multicolumn{5}{|l|}{ Medication use } \\
\hline Antiplatelet & $1.28(0.85$ to 1.91$)$ & 0.238 & - & - \\
\hline NOAC & $1.11(0.53$ to 2.33$)$ & 0.777 & - & - \\
\hline Warfarin & $0.98(0.65$ to 1.48$)$ & 0.925 & - & - \\
\hline$\beta$-blocker & $1.70(1.09$ to 2.65$)$ & 0.020 & - & - \\
\hline Calcium channel blocker & $0.93(0.60$ to 1.44$)$ & 0.745 & - & - \\
\hline Diuretic & $2.02(1.33$ to 3.08$)$ & 0.001 & - & - \\
\hline ACEI and/or ARB & 1.47 (0.98 to 2.20$)$ & 0.062 & - & - \\
\hline Statin use & $1.12(0.75$ to 1.67$)$ & 0.595 & - & - \\
\hline \multicolumn{5}{|l|}{ Echocardiographic data } \\
\hline $\operatorname{LVEF}(\%)$ & $0.98(0.97$ to 1.00$)$ & 0.033 & - & - \\
\hline $\mathrm{LAD} \geq 45 \mathrm{~mm}(\%)$ & $2.23(1.46$ to 3.40$)$ & $<0.001$ & 2.20 (1.36 to 3.56$)$ & 0.001 \\
\hline LVEDd (mm) & $1.03(1.01$ to 1.06$)$ & 0.020 & - & - \\
\hline LVESd (mm) & 1.03 (1.01 to 1.06$)$ & 0.014 & - & - \\
\hline LVPWT (mm) & 1.15 (0.97 to 1.36$)$ & 0.109 & - & - \\
\hline $\operatorname{IVST}(\mathrm{mm})$ & $1.05(0.89$ to 1.22$)$ & 0.586 & - & - \\
\hline $\operatorname{LVM}(\mathrm{g})$ & $1.00(1.00$ to 1.01$)$ & 0.016 & - & - \\
\hline Follow-up period (months) & $1.01(0.99$ to 1.02$)$ & 0.311 & - & - \\
\hline
\end{tabular}

eGFR indicates estimated glomerular filtration rate; OR, odds ratio; CI, confidence interval; aOR, adjusted odds ratio; CHF, congestive heart failure; $\mathrm{CAD}$, coronary artery disease; PAD, peripheral artery disease; COPD, chronic obstructive pulmonary disease; LDL, low-density lipoprotein; HDL, high-density lipoprotein; NOACs, non-vitamin $\mathrm{K}$ antagonist oral anticoagulants; ACEI, angiotensin-converting enzyme inhibitor; ARB, angiotensin II receptor blocker; LVEF, left ventricular ejection fraction; LAD, left atrial diameter; LVEDd, left ventricular end-diastolic dimension; LVESd, left ventricular end-systolic dimension; LVPWT, left ventricular posterior wall thickness; IVST, interventricular septal thickness; and LVM, left ventricular mass.

$\mathrm{CHADS}_{2}$ and $\mathrm{CHA}_{2} \mathrm{DS}_{2}$-VASc scores. Previous studies have also assessed the relationship between single baseline eGFR values and the risk of future stroke in patients with $\mathrm{AF}^{33)}$ Recent studies proposed that renal dysfunction had an additive effect with the $\mathrm{CHADS}_{2}$ or $\mathrm{CHA}_{2} \mathrm{DS}_{2}$-VASc scores, thus improving their predictive ability; ${ }^{34,35)}$ in contrast, two recent "real-world" cohort studies found no additive effect of renal impairment in the ability of these scores to predict thromboembolism. ${ }^{36,37)}$ In contrast to previous studies, some studies reported progressive renal 
function decline and subsequent risk of stroke or death in patients with $\mathrm{AF}^{4,23)}$

Potential mechanisms for the association between AF and CKD progression include systemic inflammation, repeated microemboli, and hemodynamic factors. ${ }^{38)} \mathrm{AF}$ promotes systemic inflammation, which has been strongly related with progression of $\mathrm{CKD}$. In addition, $\mathrm{AF}$ can induce fibrosis of the myocardium as well as kidney fibrosis, perhaps through a systemic pro-fibrotic tendency. ${ }^{38)}$ Moreover, AF contributes to deterioration of left ventricular systolic and diastolic function over time, which may promote CKD progression through altered hemodynamics, venous congestion, and activation of the reninangiotensin-aldosterone system. ${ }^{39)}$ Indeed, eGFR improved in patients whose AF was ablated successfully, compared with patients whose arrhythmia persisted after ablation intervention. ${ }^{40)}$

There were some limitations to this study. First, the LA volume may provide a more accurate estimate of the LA chamber than LAD. However, we used LAD because it is easier to measure and is more frequently used in routine echocardiographic evaluations..$^{24,26,41)}$ Second, this was an observational retrospective study; thus, we cannot infer causality from the observed associations. Third, we only included hospitalized patients in the registry; thus, selection bias cannot be ruled out. However, our study mainly focused on patients with a high risk of stroke. Fourth, only $7.9 \%$ of the included patients were taking NOACs, but $40.6 \%$ were taking antiplatelet drugs and $40.9 \%$ were taking warfarin. Thus, our patient population reflects a "real life" cohort of Chinese patients with AF who have a high risk of stroke and do not adhere to treatment guidelines. ${ }^{42)}$

\section{Conclusions}

In conclusion, our study showed that older age, low baseline eGFR, CHF, and albuminuria were significant risk factors for a large decline of renal function in hospitalized AF patients with CKD stages 1-3. Moreover, LAD $\geq 45 \mathrm{~mm}$ was independently associated with a greater deterioration of renal function.

\section{Disclosure}

Ethics approval and consent to participate: This study was approved by the ethics committee of Department of Cardiovascular Medicine, the Second Affiliated Hospital of Nanchang University. All procedures performed in studies involving human participants were in accordance with the ethical standards of the institutional and/or national research committee and with the 1964 Helsinki declaration and its later amendments or comparable ethical standards.

Availability of data and material: The datasets used and/or analyzed during the current study are available from the corresponding author upon request.

Conflicts of interest: The authors declare that they have no conflicts of interest.

\section{References}

1. Fuster V, Rydén LE, Cannom DS, et al. ACC/AHA/ESC. ACC/ AHA/ESC 2006 Guidelines for the Management of Patients with atrial fibrillation: a report of the American College of Cardiology/American Heart Association Task Force on Practice Guidelines and the European Society of Cardiology Committee for Practice Guidelines (Writing Committee to Revise the 2001 Guidelines for the Management of Patients with atrial fibrillation): developed in collaboration with the European Heart Rhythm Association and the Heart Rhythm Society. Circulation 2006; 114: e257-354.

2. Alonso A, Lopez FL, Matsushita K, et al. Chronic kidney disease is associated with the incidence of atrial fibrillation: the Atherosclerosis Risk in Communities (ARIC) study. Circulation 2011; 123: 2946-53.

3. Soliman EZ, Prineas RJ, Go AS, et al. Chronic kidney disease and prevalent atrial fibrillation: the Chronic Renal Insufficiency Cohort (CRIC). Am Heart J 2010; 159: 1102-7.

4. Guo Y, Wang H, Zhao X, et al. Sequential changes in renal function and the risk of stroke and death in patients with atrial fibrillation. Int J Cardiol 2013; 168: 4678-84.

5. Yao X, Tangri N, Gersh BJ, et al. Renal outcomes in anticoagulated patients with atrial fibrillation. J Am Coll Cardiol 2017; 70: 2621-32.

6. Fanola CL, Mooney D, Cowan AJ, et al. Incidence of severe renal dysfunction among individuals taking warfarin and implications for non-vitamin K oral anticoagulants. Am Heart J 2017; 184: $150-5$.

7. Hijazi Z, Hohnloser SH, Andersson U, et al. Efficacy and safety of Apixaban compared with warfarin in patients with atrial fibrillation in relation to renal function over time: insights from the Aristotle randomized clinical trial. JAMA Cardiol 2016; 1: 451-60.

8. Chen SC, Lee WH, Hsu PC, et al. Association of the ratio of early mitral inflow velocity to the global diastolic strain rate with a rapid renal function decline in atrial fibrillation. PLOS ONE 2016; 11: e0147446.

9. Violi F, Pastori D, Perticone F, et al. Relationship between low Ankle-Brachial Index and rapid renal function decline in patients with atrial fibrillation: a prospective multicentre cohort study. BMJ Open 2015; 5: e008026.

10. Beyer-Westendorf J, Kreutz R, Posch F, Ay C. The CHA2DS2VASc score strongly correlates with glomerular filtration rate and predicts renal function decline over time in elderly patients with atrial fibrillation and chronic kidney disease. Int J Cardiol 2018; 253: 71-7.

11. Chen SC, Chang JM, Tsai YC, et al. Ratio of transmitral Ewave velocity to early diastole mitral annulus velocity with cardiovascular and renal outcomes in chronic kidney disease. Nephron Clin Pract 2013; 123: 52-60.

12. Chen SC, Su HM, Hung CC, et al. Echocardiographic parameters are independently associated with rate of renal function decline and progression to dialysis in patients with chronic kidney disease. Clin J Am Soc Nephrol 2011; 6: 2750-8.

13. Lang RM, Bierig M, Devereux RB, et al. Recommendations for chamber quantification: a report from the American Society of Echocardiography's Guidelines and Standards Committee and the Chamber Quantification Writing Group, developed in conjunction with the European Association of Echocardiography, a branch of the European Society of Cardiology. Journal of the American Society of Echocardiography: official publication of the American Society of Echocardiography 2005; 18: 1440-63.

14. Lip GY, Nieuwlaat R, Pisters R, Lane DA, Crijns HJ. Refining clinical risk stratification for predicting stroke and thromboembolism in atrial fibrillation using a novel risk factor-based approach: the euro heart survey on atrial fibrillation. Chest 2010; 137: $263-72$

15. Levey AS, Stevens LA, Schmid CH, et al. A new equation to estimate glomerular filtration rate. Ann Intern Med 2009; 150: 
604-12.

16. National Kidney F. K/DOQI clinical practice guidelines for chronic kidney disease: evaluation, classification, and stratification. American journal of kidney diseases: the official journal of the National Kidney Foundation 2002; 39: S1-266.

17. Levey AS, Inker LA, Matsushita K, et al. GFR decline as an end point for clinical trials in CKD: a scientific workshop sponsored by the National Kidney Foundation and the US Food and Drug Administration. Am J Kidney Dis 2014; 64: 821-35.

18. Olshansky B, Heller EN, Mitchell LB, et al. Are transthoracic echocardiographic parameters associated with atrial fibrillation recurrence or stroke? Results from the Atrial Fibrillation Follow-Up Investigation of Rhythm Management (AFFIRM) study. J Am Coll Cardiol 2005; 45: 2026-33.

19. Chang WX, Asakawa S, Toyoki D, et al. Predictors and the subsequent risk of end-stage renal disease - usefulness of $30 \%$ decline in estimated GFR over 2 years. PLOS ONE 2015; 10: e0132927.

20. Chang WX, Arai S, Tamura Y, et al. Time-dependent risk factors associated with the decline of estimated GFR in CKD patients. Clin Exp Nephrol 2016; 20: 58-70.

21. Goette A, Kalman JM, Aguinaga L, et al. EHRA/HRS/APHRS/ SOLAECE expert consensus on Atrial cardiomyopathies: definition, characterisation, and clinical implication. J Arrhythm 2016; 32: $247-78$.

22. Fuster V, Rydén LE, Asinger RW, et al. ACC/AHA/ESC. ACC/ AHA/ESC Guidelines for the management of patients with atrial fibrillation: executive summary A report of the American College of Cardiology/American Heart Association Task Force on Practice Guidelines and the European Society of Cardiology Committee for Practice Guidelines and policy conferences (Committee to Develop guidelines for the management of patients with atrial fibrillation) developed in collaboration with the North American Society of Pacing and Electrophysiology. Circulation 2001; 104: 2118-50.

23. Roldán V, Marín F, Fernández $\mathrm{H}$, et al. Renal impairment in a 'real-life' cohort of anticoagulated patients with atrial fibrillation (implications for thromboembolism and bleeding). Am J Cardiol 2013; 111: 1159-64.

24. Kizer JR, Bella JN, Palmieri V, et al. Left atrial diameter as an independent predictor of first clinical cardiovascular events in middle-aged and elderly adults: the Strong Heart Study (SHS). Am Heart J 2006; 151: 412-8.

25. Abhayaratna WP, Seward JB, Appleton CP, et al. Left atrial size: physiologic determinants and clinical applications. J Am Coll Cardiol 2006; 47: 2357-63.

26. Hamatani Y, Ogawa H, Takabayashi K, et al. Left atrial enlargement is an independent predictor of stroke and systemic embolism in patients with non-valvular atrial fibrillation. Sci Rep 2016; 6: 31042 .

27. Furukawa M, Io H, Tanimoto M, Hagiwara S, Horikoshi S, Tomino Y. Predictive factors associated with the period of time before initiation of hemodialysis in CKD stages 4 and 5. Nephron Clin Pract 2011; 117: c341-7.

28. Kim SJ, Han SH, Park JT, et al. Left atrial volume is an independent predictor of mortality in CAPD patients. Nephrol Dial Transplant 2011; 26: 3732-9.
29. Bolignano D, Mattace-Raso F, Sijbrands EJ, Zoccali C. The aging kidney revisited: a systematic review. Ageing Res Rev 2014; 14: $65-80$

30. Perkins RM, Kirchner HL, Hartle JE, Bucaloiu ID. Estimated glomerular filtration rate variability and risk of end-stage renal disease among patients with Stage 3 chronic kidney disease. Clin Nephrol 2013; 80: 256-62.

31. Halbesma N, Kuiken DS, Brantsma AH, et al. Macroalbuminuria is a better risk marker than low estimated GFR to identify individuals at risk for accelerated GFR loss in population screening. J Am Soc Nephrol 2006; 17: 2582-90.

32. Turin TC, James M, Ravani $\mathrm{P}$, et al. Proteinuria and rate of change in kidney function in a community-based population. J Am Soc Nephrol 2013; 24: 1661-7.

33. Olesen JB, Lip GY, Kamper AL, et al. Stroke and bleeding in atrial fibrillation with chronic kidney disease. $\mathrm{N}$ Engl $\mathrm{J}$ Med 2012; 367: 625-35.

34. Piccini JP, Stevens SR, Chang Y, et al. Renal dysfunction as a predictor of stroke and systemic embolism in patients with nonvalvular atrial fibrillation: validation of the R (2)CHADS(2) index in the ROCKET AF (Rivaroxaban once-daily, oral, direct factor Xa inhibition compared with vitamin $\mathrm{K}$ antagonism for prevention of stroke and embolism trial in atrial fibrillation) and ATRIA (AnTicoagulation and Risk factors In Atrial fibrillation) study cohorts. Circulation 2013; 127: 224-32.

35. Chao TF, Tsao HM, Ambrose K, et al. Renal dysfunction and the risk of thromboembolic events in patients with atrial fibrillation after catheter ablation--the potential role beyond the CHA (2)DS(2)-VASc score. Heart Rhythm 2012; 9: 1755-60.

36. Roldán V, Marín F, Manzano-Fernandez S, et al. Does chronic kidney disease improve the predictive value of the CHADS2 and CHA2DS2-VASc stroke stratification risk scores for atrial fibrillation? Thromb Haemost 2013; 109: 956-60.

37. Banerjee A, Fauchier L, Vourc'h P, et al. Renal impairment and ischemic stroke risk assessment in patients with atrial fibrillation: the Loire Valley Atrial Fibrillation Project. J Am Coll Cardiol 2013; 61: 2079-87.

38. Bansal N, Fan D, Hsu CY, Ordonez JD, Go AS. Incident atrial fibrillation and risk of death in adults with chronic kidney disease. J Am Heart Assoc 2014; 3: e001303.

39. Franczyk-Skóra B, Gluba A, Olszewski R, Banach M, Rysz J. Heart function disturbances in chronic kidney disease - echocardiographic indices. Arch Med Sci 2014; 10: 1109-16.

40. Navaravong L, Barakat M, Burgon N, et al. Improvement in estimated glomerular filtration rate in patients with chronic kidney disease undergoing catheter ablation for atrial fibrillation. J Cardiovasc Electrophysiol 2015; 26: 21-7.

41. Gerdts E, Wachtell K, Omvik P, et al. Left atrial size and risk of major cardiovascular events during antihypertensive treatment: losartan intervention for endpoint reduction in hypertension trial. Hypertension 2007; 49: 311-6.

42. Henrard S, Vandenabeele C, Marien S, Boland B, Dalleur O. Underuse of anticoagulation in older patients with atrial fibrillation and CHADS2 score $\geq 2$ : are we doing better since the marketing of direct oral anticoagulants? Drugs Aging 2017; 34: $841-50$. 